quickly changing. Of course, if the names of the authors of subsections or chapters are identical with those of the leading workers in special branches then most authoritative accounts can be expected. This is the case with the contributions in the present volume dealing with virology, including oncolytic viruses, carcinogenesis and tumour biochemistry. However, frequently one cannot escape the impression of having read similar reports, sometimes by the same authors, in other collections. Consequently, the reader is torn between his desire to go back to the original papers and his inclination to skim superficially over the texts of the reviews. Another criticism which can be raised against this specific volume is that, under the heading "Progress in Tumour Inhibition", a review of cytotoxic agents of the purine and the steroid group is presented which refers only to compounds synthesized by Lettré and his colleagues and mainly tested on cell cultures. The article by Sokoloff on oncolytic antibiotics is fascinating from the point of view of combination therapy with reticulo-endothelial system activators, such as hæmatoporphyrin and congo red, but it deals solely with four mould products which, so far as one knows, do not belong to the same chemical family.

There is no desire to throw doubt on the value, which is considerable, of this progress report. However, and this question can be raised with a large number of others of a similar type and of high quality, are these progress reports "really necessary ?" It is suggested that the answer lies mainly with the review authors, who in future should have the strength of mind to turn down requests for reviews and only accept the task of writing a few inside a period of three to five years. It is not certain which of us would have this strength.

F. Bergel

\section{ILLUSTRATIONS OF HUMAN ANATOMY}

\section{Atlas of Human Anatomy}

Edited by Prof. Ferenc Kiss and Prof. János Szentágothai. Contributor: István Munkácsi. Vol. 1: Osteology-Syndesmology-Myology. Pp. 297. Vol. 2: Splanchnology-Endocrine Glands-Heart. Pp. 214. Vol. 3: Nervous System-Vascular SystemLymphatic System-Sense Organs. Pp. 289. Eighth edition. (Budapest: Publishing House of the Hungarian Academy of Sciences-Publishing House Medicina; London: Collet's Holdings Ltd. 1960.) $180 s$. the three volumes.

$\mathrm{T}$

HE pioneer work in the field of modern anatomical illustration we owe to Andreas Vesalius, who published his De Corporis Humani Fabrica in 1547. It is true that Leonardo da Vinei produced a considerable number of magnificent anatomical drawings - with the legend in his characteristic mirror writing -but for various reasons these never attained the wide circulation and popularity of the drawings prepared by Vesalius.

The Vesalian illustrations were in black-and-white. Aselli's work, De Lactibus Sive Lacteis Venis, published in Milan in 1627, contained the first anatomical illustrations in colour. It is a far cry from Aselli's few simple woodcuts to our modern profusely illustrated anatomical atlases, all of which have followed Aselli's lead in making liberal use of colour.

It is generally assumed that the art of anatomical illustration has improved greatly since the time of
Vesalius; but it is questionable whether this is entirely true. One of the striking differences between the Vesalian drawings and those found in modern atlases, such as that now before us, is the way in which Vesalius repeatedly depicted the body as a whole, more especially in relation to the skeletal and muscular systems. Though to do this adequately requires plates which are too large for a volume of average size, it possesses very considerable advantages.

Again, it is not clear what purpose is served by the indiscriminate use of colour. Where the colours used resemble those in the original, the illustration will be of value in recalling the dissection which it is intended to portray. Where, however, the colours are purely conventional and bear little or no resemblance to the original, their value becomes very problematical. They may be magnificent, but they are not anatomy. It is far easier with the eye of the mind to superimpose the colours of the original on a black-and-white diagram than on a diagram with colours so greatly at variance with the original that it becomes impossible to substitute the latter for the former.

The Atlas now before us is on the whole well done. The illustrations frequently tend to be schematic, but that is a feature common to most modern atlases. The authors have commendably allowed the illustra. tions to explain themselves, and have refrained from burdening the reader with superfluous legend. Vol. 1 depicts bones, joints, muscles and fasciæ. Vol. 2 deals with viscera, endocrine glands, and heart; and Vol. 3 is devoted to the nervous, vascular and lymphatic systems, concluding with the sense organs.

It would appear from the preface that this Atlas has attained great popularity in countries behind the Iron Curtain, and that a Chinese edition has been prepared by Prof. Yü-Ch'üang Tsang.

\section{J. M. YOFFEY}

\section{RUSSIAN WORK IN ORGANO- PHOSPHORUS CHEMISTRY}

\section{Soviet Research on Organo-Phosphorus Com-} pounds, 1949-1956

In English Translation. Part 1 : Pp. viii +448 . 50 dollars. Part 2 : Pp. vii $+449-890$. 50 dollars. Part 3 : Pp. iv + 891-1208. 30 dollars. Complete collection, 120 dollars. (Chemistry Collection Series.) (New York : Consultants Bureau, Inc., 1960.)

URING the past two decades, there has been a great resurgence of interest in the chemistry of organo-phosphorus compounds, both on the purely scientific side and on the technical side: the academic chemist is attracted by the many novel reactions of these compounds, and the technical chemist by their potential application for a variety of purposes. This resurgence of interest has been strongly marked in chemical studies in the United States and the U.S.S.R.; but in Britain, apart from certain manufacturing processes, the interest has appeared to be very much less active, possibly because the new work has tended to be in highly specialized fields.

The Russian contributions to organo-phosphorus chemistry have naturally been published almost entirely in Russian, and consequently these contributions, although very considerable, have not been easily and rapidly available to English-speaking chemists. The latter are now deeply in debt both to Prof. Alfred Burger of the University of Virginia, 